\title{
Asthmatic bronchial hyperresponsiveness varies with ambient levels of summertime air pollution
}

\author{
S.C.O. Taggart*, A. Custovic*, H.C. Francis*, E.B. Faragher**, \\ C.J. Yates ${ }^{+}$, B.G. Higgins*, A. Woodcock*
}

Asthmatic bronchial hyperresponsiveness varies with ambient levels of summertime air pollution. S.C.O. Taggart, A. Custovic, H.C. Francis, E.B. Faragher, C.J. Yates, B.G. Higgins, A. Woodcock. @ERS Journals Ltd 1996.

ABSTRACT: It is widely believed that the mechanisms of action of outdoor air pollutants are the same as those found in the laboratory, although few studies have attempted to clarify this issue. This study investigates the relationship of asthmatic bronchial hyperresponsiveness (BHR), a marker of airway inflammation, and pulmonary function to ambient levels of summertime air pollution.

Thirty eight nonsmoking adult asthmatic subjects underwent repeated measurement of methacholine BHR, using Yan's method, at differing levels of air pollution $\left(\mathrm{O}_{3}, \mathrm{SO}_{2}, \mathrm{NO}_{2}\right.$, smoke) during summer 1993.

A total of 109 evaluable tests were performed: 31 subjects completed three or more challenge tests, and seven managed two. Levels of all pollutants remained within current World Health Organization (WHO) Guidelines for Health. Changes in BHR were found to correlate significantly with changes in the levels of $24 \mathrm{~h}$ mean $\mathrm{SO}_{2}, \mathrm{NO}_{2}$ and smoke; $48 \mathrm{~h}$ mean $\mathrm{NO}_{2}$ and smoke; $24 \mathrm{~h}$ lag $\mathrm{NO}_{2}$; although the effect was only small, accounting for approximately $10 \%$ of the variability in within-subject BHR between visits. Twenty four hour lag $\mathrm{NO}_{2}$ was also associated with forced vital capacity (FVC).

In conclusion, in subjects with asthma, methacholine bronchial hyperresponsiveness varies with ambient levels of summertime air pollution. This suggests that changes in airway inflammation underlie the increased respiratory morbidity known to accompany pollution episodes.

Eur Respir J., 1996, 9, 1146-1154.
*North West Lung Centre, Wythenshawe Hospital, Manchester, UK. **Department of Medical Statistics, University Hospital of South Manchester, Manchester, UK. +Dept of Environmental Health, Halton Borough Council, Widnes, Cheshire, UK.

Correspondence: S.C.O. Taggart

Dept of Thoracic Medicine

Royal Free Hospital

Pond Street

London NW3 2QG

UK

Keywords: Air pollution

asthma

bronchial hyperresponsiveness

Received: March 301995

Accepted after revision February 221996
Over the past two decades, environmental chamber studies have played an important role in characterizing the response of normal and asthmatic volunteers to a variety of commonly occurring air pollutants. These studies have been instrumental in the identification of atrisk groups, the determination of thresholds of effect, and the elucidation of mechanisms of action. However, the artificial circumstances under which exposure protocols are performed may not adequately reflect the conditions under which exposure takes place in the natural environment. In particular, the duration of exposure is often only short, the concentration of pollutant remains constant, and in order to demonstrate effects at ambient pollutant levels, vigorous programmes of exercise are often included in the protocol. In contrast, exposure to outdoor pollutants may be more prolonged, pollutant levels tend to vary on a daily basis, and estimates of exposure are complicated by individual movement in and out of doors. Despite these discrepancies, the findings from epidemiological studies are in broad agreement with those from the chamber but effects have tended to occur at lower concentrations of pollution, possibly as a result of the action of ambient co-factors or pollutant interactions $[1,2]$.
We have previously demonstrated that relatively low levels of summertime ozone $\left(\mathrm{O}_{3}\right)$ and sulphur dioxide $\left(\mathrm{SO}_{2}\right)$ air pollution are independently associated with peak expiratory flow rate (PEFR) measurements, respiratory symptoms and medication use in subjects with asthma and chronic bronchitis [3]. Evidence from laboratory exposures to these pollutants suggests that these effects are mediated by differing mechanisms of action: inhalation of $\mathrm{SO}_{2}$ produces a transient reflex bronchoconstriction, easily inhibited by the administration of a beta-adrenoreceptor agonist [4]; whereas, exposure to $\mathrm{O}_{3}$ induces airway inflammation (in itself capable of producing bronchoconstriction) and causes stimulation of pain receptors leading to a decrease in lung volumes $[5$, 6].

It is widely believed that similar mechanisms of action are in operation in the outdoor environment, although few investigations have attempted to clarify this issue. It is, however, important to determine the mechanisms of action of pollutants in the outdoor environment, since, where effects are mediated by changes in airway calibre alone, removal from pollution can be expected to be followed by rapid resolution of symptoms. Changes in airway inflammation are, on the other hand, likely to 
manifest as more persistent symptoms but, in addition, might be important in lowering the threshold for effects and in modifying the response to a variety of other environmental factors [7, 8]. This has important implications to health but in particular to the rising number of asthma sufferers [9], who are exposed to a constantly rising concentration of vehicle exhaust pollution [10].

In the laboratory, asthmatic airway inflammation is best measured by direct sampling of the bronchial mucosa and harvesting of cells and inflammatory mediators with fibreoptic bronchoscopic biopsy/bronchoalveolar lavage $[11,12]$. In the epidemiological setting, airway inflammation is indirectly reflected by the response to inhaled nonspecific bronchoconstrictors with which it is known to correlate $[11,12]$.

This study sets out to investigate whether asthmatic bronchial hyperresponsiveness (BHR) and basic pulmonary function vary with ambient levels of summertime air pollution in an area where air pollution has been found previously to be a problem.

\section{Methods}

\section{Study setting}

The entire study was performed in the urban-industrialized, medium-sized British towns of Runcorn and Widnes (total population of 120,000 inhabitants), which straddle the river Mersey in the Northwest of England. The study area is characterized by a number of potential local sources of air pollution, including a variety of chemical manufacturing and processing plants, a network of urban roads, a motorway $6 \mathrm{~km}$ to the southeast, and a 2,000 megawatt, nondesulphurized, coal-fired electrical generating power station (Fiddlers Ferry) to the east. In addition, up to 60,000 vehicles of commuter traffic pass through the centre of each town daily.

\section{Study population}

In each town, a suitable general practitioner (GP) surgery was identified, from which to enrol subjects (Brookvale Practice in Runcorn and Appleton Surgery in Widnes), and whose catchment area lay close to the pollution monitoring sites. The names of all nonsmoking asthmatic subjects, aged $18-70 \mathrm{yrs}$, who were contactable by telephone and were living and working within $4 \mathrm{~km}$ of their respective pollution monitoring site were collected from the asthma registers of both practices. All subjects had previously been found by their GP to give typical histories of asthma and, in addition, had demonstrated greater than $15 \%$ reversibility to inhaled bronchodilator and/or at least $20 \%$ daily PEFR variability (maximum PEFR - minimum PEFR/maximum PEFR) $\times$ 100 on at least one occasion during a 2 week period of measurement.

A total of 205 potential study subjects were identified and all were sent letters of information jointly signed by the principal investigator and respective GP. Subjects were requested to return a slip of paper in the prepaid envelope provided, indicating whether they were or were not interested in taking part.

\section{Study protocol}

The study was approved by the Research and Ethics Committees of both Halton Borough Council and the University Hospitals of South Manchester and recruitment commenced on the 17th July 1993. Each responder to the information letter was contacted by telephone and their current asthma status was assessed by the principal investigator (with training in respiratory medicine). If they were clinically stable and no changes had been made to their asthma medication in the previous 3 months, and providing they were lifelong nonsmokers or ex-smokers of more than $1 \mathrm{yr}$ and were not taking either regular oral steroids, long-acting oral/inhaled bronchodilators, or inhaled anticholinergics, an appointment was made for them to attend their respective GP for testing.

Prior to entry, each subject received a full explanation of the study and gave their consent. In order to blind subjects to the study objectives and, thereby, minimize selection biases, participants believed they were enrolling in a study designed to investigate whether bronchial hyperresponsiveness and simple measures of lung function varied with time, and what factors determined individual response to methacholine. Basic demographic details and medication use were recorded on a separate piece of paper and subjects then underwent skin-prick testing to four common allergens: Dermatophagoides pteronyssinus, cat, trees, and grasses (E. Merck Ltd, Alton, Allergopharma, Germany; Bio Diagnostics, Upton-Upon-Severn, UK) with histamine and saline solutions as controls. All skinprick tests were performed by the principal investigator and were read after $15 \mathrm{~min}$. A positive response was defined as a skin weal diameter of at least $3 \mathrm{~mm}$ more than the saline control.

The age and height of all subjects were measured and predicted values for forced expiratory volume in one second (FEV1) were then determined. Baseline pulmonary function was measured, corrected for body temperature, atmospheric pressure and water saturation (BTPS), on a dry bellows spirometer (Vitalograph, Buckingham, $\mathrm{UK}$ ), and FEV1 and forced vital capacity (FVC) were recorded as the best of three blows within $150 \mathrm{~mL}$ or $5 \%$ of one another. Prior to testing, all subjects were required to do without any short-acting inhaled bronchodilators for $6 \mathrm{~h}$. Providing baseline FEV1 was within $60 \%$ of predicted, the $\mathrm{FEV} 1 / \mathrm{FVC}$ ratio was greater than $50 \%$, and there were no absolute contraindications, subjects then underwent a methacholine bronchial challenge using the method of YAN et al. [13].

\section{Methacholine bronchial challenge}

Following the measurement of baseline spirometry, three inhalations of normal saline were administered from a handheld De Vilbiss No. 40 glass nebulizer (De Vilbiss, Somerset, UK) and FEV1 was recorded 1 min later taking the best of a further two blows within 100 $\mathrm{mL}$ of each other. Starting from $0.05 \mu \mathrm{mol}$, sequential doubling doses of methacholine were inhaled from different, individually calibrated De Vilbiss No. 40 nebulizers to a maximum of $12.5 \mu \mathrm{mol}$ methacholine, or until FEV1 fell by $20 \%$ or more from baseline. A positive response was defined as the cumulative provocative dose 
of methacholine causing a $20 \%$ drop in the postsaline FEV1 (PD20FEV1). This was estimated using linear interpolation between log doses. All positive responders were given an inhaled $\beta_{2}$-agonist (salbutamol $200 \mu \mathrm{g}$ ) via a spacer device and were allowed to return home once their FEV1 had increased to $90 \%$ baseline.

\section{Pollution monitoring}

Halton Borough Council has routinely monitored $\mathrm{SO}_{2}$ and smoke air pollution in the area since the 1960s but in 1990 purchased new equipment that uses differential absorption spectroscopy (OPSIS $®$, Sweden) to provide a continuous analysis of a variety of pollutants. A beam of light at visible and ultraviolet frequencies is transmitted to a receiver approximately $500 \mathrm{~m}$ away. The receiver contains an optical fibre system connected to a spectrometer, which scans the light beam and determines which frequencies have been absorbed by gases traversing the beam. Since pollutant gases each absorb light at a characteristic frequency, the atmospheric concentration of the selected gases can be determined. The spectrometer is linked to a computerized recording system, which stores pollutant levels continuously. The system can, therefore, be used to determine pollution levels at a particular time-point or levels can be averaged over a time period. In this study, $24 \mathrm{~h}$ mean levels were used.

Two receivers are situated in the Halton District, one at a height of $32 \mathrm{~m}$ (Municipal Building in Widnes) and the other at $12 \mathrm{~m}$ (Runcorn Town Hall). Both receive light traversing a representative area of each town from sources placed $12 \mathrm{~m}$ above the ground and at a distance of $500 \mathrm{~m}$ away. The system is, therefore, ideal for measuring background concentrations of commonly occurring urban air pollutants but cannot be used to provide information on particulate matter. The system has a detection limit of $0.5 \mu \mathrm{g} \cdot \mathrm{m}^{-3}$, is accurate to within 1.0 $\mu \mathrm{g} \cdot \mathrm{m}^{-3}$, and is comparable with standard measurements of pollution [14].

Daily mean concentrations (for any $24 \mathrm{~h}$ period) of $\mathrm{NO}_{2}, \mathrm{SO}_{2}$ and $\mathrm{O}_{3}$ were monitored continuously by OPSIS ${ }$. In addition, daily mean background concentrations of particulate matter were collected using the blacksmoke method [15], at ground level outside the buildings where OPSIS ${ }^{\circledR}$ measurements were made and at a distance of $50 \mathrm{~m}$ from the nearest road. Particles were collected onto a single filter paper for each $24 \mathrm{~h}$ period, starting at 0900 $\mathrm{h}$ each day. All pollutant exposure variables were expressed as $\mu \mathrm{g} \cdot \mathrm{m}^{-3}$. Daily mean temperature was also recorded $\left({ }^{\circ} \mathrm{C}\right)$. All measurements were kindly performed by a team of dedicated environmental scientists based at Halton Borough Council.

\section{Pollen collection}

Daily levels of grass and tree pollen were collected using a standard Burkard trap $15 \mathrm{~km}$ to the southwest by the local pollen station (data kindly supplied by $\mathrm{C}$. Murphy of "The Geochem Group", Chester, UK) and results are expressed as grains $\cdot \mathrm{m}^{-3}$ for the $24 \mathrm{~h}$ period commencing at $0900 \mathrm{~h}$ each day.

\section{Repeated bronchial challenge tests}

Those subjects with a PD20FEV1 of less than 12.5 umol methacholine ("reactors") were recruited into the current study to investigate whether asthmatic bronchial hyperresponsiveness (BHR) varies with air pollution, and their recruitment PD20FEV1s were carried forward for inclusion into the main study analysis.

This involved performing repeat bronchial challenge tests at differing levels of pollution. During the $48 \mathrm{~h}$ prior to testing, subjects were required not to leave the study area. Each subject was assigned to the same challenge test operator using the same equipment, and was tested at the same time on each visit to minimize effects due to differences in operator technique and diurnal variation in clinical disease. The principal investigator used 4 day local meteorological forecasts (supplied by the local Meteorological Office) complemented by privileged access to pollution data, to predict changes in the levels of pollution and organize recruitment for testing. Analysis of the OPSIS ${ }^{\circledR}$ data from the previous summer had revealed a strong relationship between the levels of $\mathrm{NO}_{2}$ and wind speed $(\mathrm{r}=0.74 ; \mathrm{p}<0.001)$, and a less strong association for $\mathrm{SO}_{2}(\mathrm{r}=0.42 ; \mathrm{p}<0.001)$. In contrast, levels of $\mathrm{O}_{3}$ were primarily influenced by temperature. In general, a rise in pollution was expected during anticyclonic weather conditions, and a fall in pollution with low pressure weather fronts.

Each individual's progress was monitored throughout the study to ensure that their BHR was measured on at least two separate occasions when the $24 \mathrm{~h}$ mean levels of total pollution $\left(\mathrm{NO}_{2}+\mathrm{SO}_{2}+\mathrm{O}_{3}+\right.$ smoke) differed by an arbitrarily defined magnitude of 2 . BHR testing, therefore, took place on days when pollution was expected to be relatively "high" and on days when it was expected to be relatively "low". All recruitment PD20FEV1s were performed at a time when pollution levels were "low" and, in order to minimize any learning effects, half of the group were randomly assigned to have their second measurement of PD20FEV1 performed when pollution was expected to be "high" and the other half when pollution was expected to be "low". Those subjects tested on sequential "lows" were tested again where possible when pollution was "high", whilst those on a "low" and "high" were again randomly tested either on a "low" or "high" day. Appointments were made on the telephone by the principal investigator, who kept all subjects and other investigators blinded to pollution levels. The principal investigator played no part in the testing of subjects.

\section{Statistical analysis}

A log-linear relationship was identified between all lung function measures and pollutant levels, grass pollen concentrations and temperature. The previous $24 \mathrm{~h}$ mean and $48 \mathrm{~h}$ mean of each pollutant $\left(\mathrm{NO}_{2}, \mathrm{SO}_{2}, \mathrm{O}_{3}\right)$ and temperature was individually calculated to allow for the different times that subjects presented for testing. To allow for a lagged effect, the $24 \mathrm{~h}$ mean for the period commencing $48 \mathrm{~h}$ and ending $24 \mathrm{~h}$ before each challenge was also calculated ( $24 \mathrm{~h} \mathrm{lag}$ ). It was not possible to allow for the differences in time of testing when 
calculating individual exposures to smoke pollution and pollen, as data were collected for a $24 \mathrm{~h}$ period commencing at $0900 \mathrm{~h}$ each day. The $24 \mathrm{~h}$ mean exposure variable, therefore, represents the average exposure from $0900 \mathrm{~h}$ the previous day to $0900 \mathrm{~h}$ on the day of testing. The $48 \mathrm{~h}$ mean represents the average exposure over a period of 2 days commencing at 0900 h 2 days prior to testing and ending at $0900 \mathrm{~h}$ on the day of testing. Twenty four hour lag was again calculated starting 2 days before testing and ending at $0900 \mathrm{~h}$ on the day before testing.

The hypothesis that asthmatic methacholine BHR or simple spirometry (FEV1 or FVC) varies with ambient levels of summertime air pollution was tested using univariate nested (hierarchical) analysis of variance [16]. The analysis was limited to an investigation of withinsubject variation of the dependent variable (BHR, FEV1 or FVC); the first step of the analysis was, therefore, to remove from the total variation that component due to differences between subjects. The proportions of the within-subject variation in each of the dependent variables accounted for by each of the exposure variables in turn were then estimated, and the results expressed as Pearson correlation coefficients. To better illustrate the size of the relationship between BHR and pollution, the percentage changes in BHR associated with a 10 unit increase in each pollutant were also estimated and are reported with their $95 \%$ confidence limits. The level of significance was set at $5 \%$.

Individual plots of BHR against the $24 \mathrm{~h}$ mean of each of the four pollutants were also examined to investigate for the presence of any heterogeneity of response. A "responder" was defined as any subject demonstrating a consistent increase in BHR as levels of pollution rose, whereas "nonresponders" showed no such relationship.

Data were processed on a portable IBM computer using the statistical package GLIM 3.77 (Generalized Linear Interactive Modelling).

\section{Results}

\section{Recruitment}

The overall response rate was $187(91 \%)$, and 63 subjects $(29 \%)$ agreed to take part. Those subjects not wishing to take part did not differ in either sex or age. Recruitment commenced on the 17th July 1993 and continued until the 12th of August 1993. Forty "reactors" were identified, and a further 20 subjects had a PD20FEV1 of $>12.5 \mu \mathrm{mol}$ methacholine ("nonreactors"). In three subjects, baseline prechallenge FEV1 was $<60 \%$ predicted, which precluded challenge testing, although each had $>15 \%$ reversibility following inhaled $\beta_{2}$-agonist (salbutamol $200 \mu \mathrm{g})$.

\section{Demography}

Of the original 40 reactors, 38 completed the study. Two subjects developed infective exacerbations of their asthma requiring changes to their regular medication and
Table 1. - Demographic characteristics of 38 reactors completing the study

\begin{tabular}{|c|c|}
\hline \multicolumn{2}{|l|}{ Characteristic } \\
\hline Subjects $\mathrm{n}$ & 38 \\
\hline $\operatorname{Sex} \mathrm{M} / \mathrm{F}$ & $13 / 25$ \\
\hline Age yrs $^{\#}$ & $40(18-70)$ \\
\hline FEV1 \% pred $\#$ & $88(60-134)$ \\
\hline FEV1/FVC \%\# & $75(50-88)$ \\
\hline PD20FEV1 $\mu \mathrm{mol}^{*}$ & $1.68(0.05-11.2)$ \\
\hline Distance from OPSIS ${ }^{\circ} \mathrm{km}^{\#}$ & $2.5(0.1-4.0)$ \\
\hline Atopic $^{+}$ & $33(87)$ \\
\hline HDM atopy ${ }^{+}$ & $25(66)$ \\
\hline Cat atopy ${ }^{+}$ & $23(61)$ \\
\hline Grass atopy ${ }^{+}$ & $24(63)$ \\
\hline Tree atopy ${ }^{+}$ & $11(29)$ \\
\hline Inhaled steroid ${ }^{+}$ & $26(68)$ \\
\hline
\end{tabular}

\#: group mean, and range in parenthesis; *: geometric mean, and range in parenthesis; +: absolute value, and percentage in parenthesis. M: male; F: female; FEV1: forced expiratory volume in one second; FVC: forced vital capacity; PD20FEV1: cumulative provocative dose of methacholine causing a $20 \%$ fall in FEV1; \% pred: percentage of predicted value; HDM: house dust mite; OPSIS $®$ : equipment using differential absorption spectroscopy to continuously analyse a variety of pollutants.

were, therefore, excluded from further study. Demographic data on the 38 reactors completing the study are summarized in table 1 .

\section{Challenge tests}

From 17th July to 22nd September 1993, a total of 109 evaluable challenge tests were performed. Twenty nine subjects performed three tests; two completed four tests; and seven managed only two. Four reactors developed nonreactor status on one occasion each from recruitment PD20FEV1s of 11.17, 10.30, 2.44 and 1.04. Median (range) time between study visits was 18 (463) days. Thirty four of the 38 subjects had their BHR recorded on at least two separate occasions when the proportional change in the level of $24 \mathrm{~h}$ mean total pollution $\left(\mathrm{NO}_{2}+\mathrm{SO}_{2}+\mathrm{O}_{3}+\right.$ smoke $)$ was greater than 2 (mean $3.1 ; 95 \%$ confidence interval 3.0-3.2).

The 109 challenge tests were performed on 18 separate days, but 2 days in particular contributed to nearly $50 \%$ of readings: 24 tests were performed on 31st July (Day 15), when pollution levels were "low", and 27 tests on 18th August (Day 33), when pollution levels were "high". Levels of grass pollen were identical on both of these days $\left(9.6\right.$ grains $\left.\cdot \mathrm{m}^{-3}\right)$ and temperatures were very similar (14.3 and $14.9^{\circ} \mathrm{C}$, respectively). The temporal association between daily total pollution concentration and the number of subjects tested each day is displayed graphically in figure 1 .

\section{Pollution levels}

The levels of all pollutants remained within current WHO Guidelines for Health [17] for the duration of the study. Maximum individual exposures for each pollutant were: $\mathrm{SO}_{2} 103.7 \mu \mathrm{g} \cdot \mathrm{m}^{-3} ; \mathrm{NO}_{2} 77.5 \mu \mathrm{g} \cdot \mathrm{m}^{-3}$; and smoke 


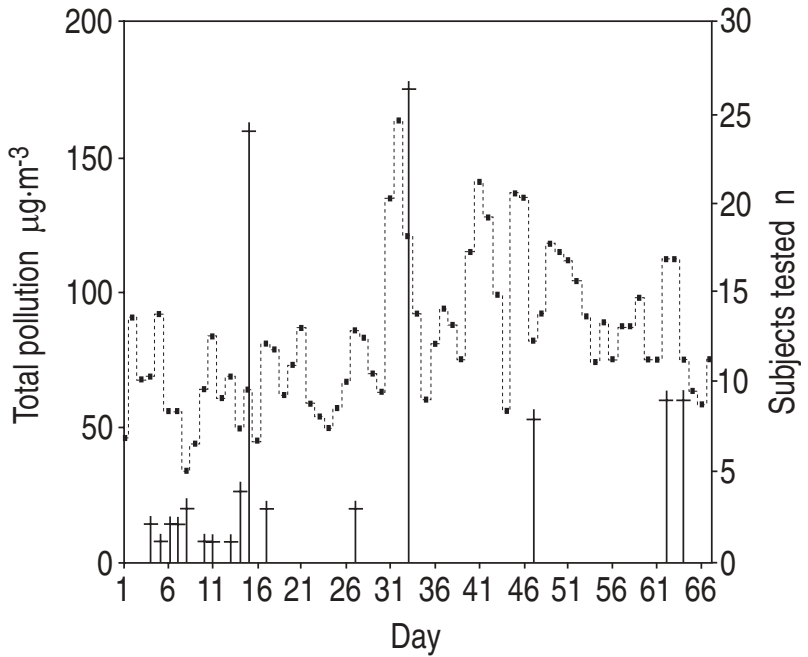

Fig. 1. - Temporal association between daily total pollution* and number of subjects tested. *: sum of daily mean $\left(\mathrm{O}_{3}+\mathrm{SO}_{2}+\mathrm{NO}_{2}+\right.$ smoke). - - - - -: daily total pollution; † : subjects.

$28 \mu \mathrm{g} \cdot \mathrm{m}^{-3}$ (WHO Guidelines for Health: 125, 150 and $125 \mu \mathrm{g} \cdot \mathrm{m}^{-3}$, respectively). Guidelines for $\mathrm{O}_{3}$ are usually given as a 1 or $8 \mathrm{~h}$ average $\left(240\right.$ and $120 \mu \mathrm{g} \cdot \mathrm{m}^{-3}$, respectively), and maximum 1,8 and $24 \mathrm{~h}$ averages in this study were 61,42 and $24.5 \mu \mathrm{g} \cdot \mathrm{m}^{-3}$, respectively.

\section{Pollen data}

Levels of tree pollen remained very low $\left(<2\right.$ grains $\left.\cdot \mathrm{m}^{-3}\right)$ for the duration of the study and were not, therefore, subjected to further analysis. The maximum concentration of grass pollen occurred early in the study (48 grains $\cdot \mathrm{m}^{-3}$ ) but had fallen to below 10 grains $\cdot \mathrm{m}^{-3}$ by $31 \mathrm{st}$ July onwards. The temporal association of daily grass pollen levels with the number of subjects undergoing BHR testing each day is illustrated in figure 2.

\section{Temperature}

Maximum daily mean temperature reached $18.1^{\circ} \mathrm{C}$ (range $11.3-18.1^{\circ} \mathrm{C}$ ).

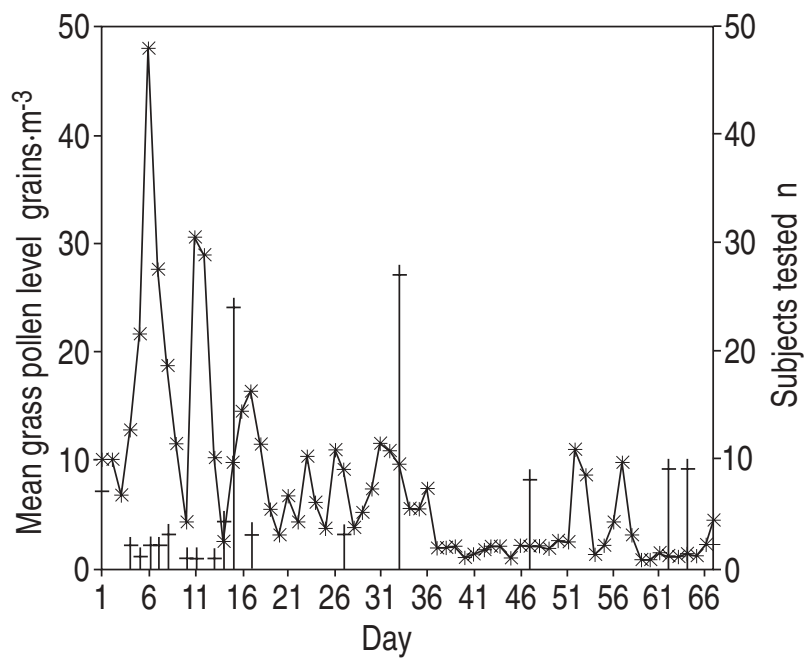

Fig. 2. - Temporal association between daily mean grass pollen levels and number of subjects tested. —— daily grass pollen level; + : subjects tested.

\section{Exposure variables}

A high degree of intercorrelation between the various explanatory variables was observed, although no associations with $\mathrm{O}_{3}$ were detected. In general, pollutants were positively correlated with one another but negatively with temperature and grass pollen. Correlation coefficients were broadly similar between $24 \mathrm{~h}$ mean, $48 \mathrm{~h}$ mean and $24 \mathrm{~h}$ lag values, although the relationship between $\mathrm{SO}_{2}$ and either $\mathrm{NO}_{2}$ or smoke was weaker at $24 \mathrm{~h}$ lag than $24 \mathrm{~h}$ mean, whereas that between temperature and either smoke or $\mathrm{NO}_{2}$ increased. Pearson correlation coefficients for $24 \mathrm{~h}$ lag values are given in table 2 .

A high degree of correlation was also found between the $24 \mathrm{~h}$ mean, $48 \mathrm{~h}$ mean and $24 \mathrm{~h}$ lag of each pollutant (all $r>0.70 ; p<0.001$ ). For each individual, the maximum change in the level of each of the 18 exposure variables was calculated (highest-lowest) and group mean (SD) results are detailed in table 3.

Associations between BHR and pollution, pollen or temperature

Twenty four hour mean levels of $\mathrm{NO}_{2}$, smoke and $\mathrm{SO}_{2}$ were all significantly negatively associated with BHR, i.e. increasing levels of pollution heightened airway responsiveness $(\mathrm{r}=-0.322, \mathrm{r}=-0.293$ and $\mathrm{r}=-0.185$, respectively; $\mathrm{p}<0.01, \mathrm{p}<0.02$ and $\mathrm{p}<0.05$, respectively). Twenty four hour mean grass pollen concentrations were also significantly associated, although the direction of change was towards an improvement in BHR with increasing values $(\mathrm{r}=0.329 ; \mathrm{p}<0.01)$.

$\mathrm{NO}_{2}$, smoke and grass pollen were significant at $48 \mathrm{~h}$ mean exposure $(r=-0.334, r=-0.242$ and $r=0.247$, respectively; $\mathrm{p}<0.01, \mathrm{p}<0.05$ and $\mathrm{p}<0.05$, respectively) but at $24 \mathrm{~h}$ lag, only the association of $\mathrm{NO}_{2}$ remained significantly related with BHR $(r=-0.254 ; \mathrm{p}<0.01)$. Furthermore, temperature gained significance at $24 \mathrm{~h}$ lag $(\mathrm{r}=0.258$; $\mathrm{p}<0.05$ ). No associations were found for $\mathrm{O}_{3}$. Table 4 summarizes the Pearson correlation coefficients for the relationship between BHR and pollution, pollen or temperature.

\section{Pulmonary function}

No effects of pollution on FEV1 were detected, although FEV1 was significantly correlated with temperature at all exposures $(r=0.279, r=0.289$ and $r=0.268$, respectively;

Table 2. - Intercorrelations between the $24 \mathrm{~h}$ lag values of the six independent variables (expressed as Pearson correlation coefficients)

\begin{tabular}{lllllll}
\hline & $\mathrm{O}_{3}$ & $\mathrm{SO}_{2}$ & $\mathrm{NO}_{2}$ & Smoke & Temp & $\begin{array}{c}\text { Grass } \\
\text { pollen }\end{array}$ \\
\hline $\mathrm{O}_{3}$ & 1.0 & 0.13 & 0.08 & 0.03 & 0.16 & 0.12 \\
$\mathrm{SO}_{2}$ & & 1.0 & $0.65^{* * *}$ & $0.48^{* * *}$ & 0.13 & -0.14 \\
$\mathrm{NO}_{2}$ & & & 1.0 & $0.89^{* * *}$ & $-0.57 * * *$ & $-0.25^{*}$ \\
Smoke & & & 1.0 & $-0.34^{* *}$ & -0.11 \\
Temp & & & & 1.0 & $0.35^{* *}$ \\
\hline
\end{tabular}

Temp: temperature. Test of significance: *: $\mathrm{p}<0.05 ; * *: \mathrm{p}<0.01$; $* * *: \mathrm{p}<0.001$. 
Table 3. - Group mean values of the maximum change in each of the six independent variables experienced by each of the 38 subjects for each of the three exposure variables

\begin{tabular}{|c|c|c|c|c|c|c|c|c|c|c|c|c|}
\hline \multirow{2}{*}{$\begin{array}{l}\text { Exposure } \\
24 \text { h mean }\end{array}$} & \multicolumn{2}{|c|}{$\begin{array}{c}\mathrm{O}_{3} \\
\mu \mathrm{g} \cdot \mathrm{m}^{-3}\end{array}$} & \multicolumn{2}{|c|}{$\begin{array}{c}\mathrm{SO}_{2} \\
\mu \mathrm{g} \cdot \mathrm{m}^{-3}\end{array}$} & \multicolumn{2}{|c|}{$\begin{array}{l}\mathrm{NO}_{2} \\
\mu \mathrm{g} \cdot \mathrm{m}^{-3}\end{array}$} & \multicolumn{2}{|c|}{$\begin{array}{l}\text { Smoke } \\
\mu \mathrm{g} \cdot \mathrm{m}^{-3}\end{array}$} & \multicolumn{2}{|c|}{$\begin{array}{c}\text { Grass pollen } \\
\text { grains } \cdot \mathrm{m}^{-3}\end{array}$} & \multicolumn{2}{|c|}{$\underset{{ }^{\circ} \mathrm{C}}{\mathrm{Temp}}$} \\
\hline & 9.7 & (4.6) & 30.2 & (10.3) & 46.6 & (10.9) & 21.1 & (6.5) & 10.7 & $(9.2)$ & 3.1 & (1.7) \\
\hline $48 \mathrm{~h}$ mean & 9.9 & (4.6) & 22.3 & $(9.8)$ & 31.1 & (9.3) & 13.8 & $(4.0)$ & 12.2 & (9.9) & 3.3 & (1.6) \\
\hline 24 h lag & 8.6 & (4.7) & 18.2 & (11.6) & 19.5 & (8.8) & 17.1 & $(4.2)$ & 14.4 & (11.4) & 3.0 & (1.6) \\
\hline
\end{tabular}

Values are presented as mean, and SD in parenthesis. Temp: temperature.

Table 4. - Pearson correlation coefficients between $\log _{e}$ BHR and each of the three $\log _{e}$ exposure variables for pollution, pollen and temperature

\begin{tabular}{lcccccc}
\hline Exposure & $\mathrm{O}_{3}$ & $\mathrm{SO}_{2}$ & $\mathrm{NO}_{2}$ & Smoke & Grass pollen & Temp \\
\hline 24 h mean & 0.029 & $-0.185^{*}$ & $-0.322 * *$ & $-0.293^{*}$ & $0.329 * *$ & 0.103 \\
48 h mean & 0.093 & -0.073 & $-0.334 * *$ & $-0.242^{*}$ & $0.247^{*}$ & 0.193 \\
24 h lag & 0.145 & 0.139 & $-0.254 * *$ & -0.154 & 0.079 & $0.258^{*}$ \\
\hline
\end{tabular}

Temp: temperature. Test of significance: *: $\mathrm{p}<0.05 ; * *: \mathrm{p}<0.01$.

$\mathrm{p}<0.02, \mathrm{p}<0.02$ and $\mathrm{p}<0.05$, respectively) and with $48 \mathrm{~h}$ mean and $24 \mathrm{~h}$ lag values of grass pollen (direction of change was towards an improvement in FEV1 with rising levels of grass pollen; $r=0.319$ and $r=0.244$, respectively; $\mathrm{p}<0.01$ and $\mathrm{p}<0.05$, respectively).

FVC was significantly associated with $24 \mathrm{~h}$ lag $\mathrm{NO}_{2}$ $(\mathrm{r}=-0.168 ; \mathrm{p}<0.05)$, and a borderline significance was found for $24 \mathrm{~h}$ mean $\mathrm{NO}_{2}(\mathrm{r}=-0.161 ; \mathrm{p}<0.06)$. No other associations were detected for either FEV1 or FVC.

\section{BHR and pulmonary function}

No significant associations or trends were found between $\mathrm{BHR}$ and either prechallenge FEV 1 or FVC $(\mathrm{r}=0.072$, $\mathrm{p}>0.10$; and $\mathrm{r}=0.11, \mathrm{p}>0.10$, respectively).

\section{Magnitude of effect of pollution on BHR}

The percentage changes in BHR $(95 \%$ confidence interval) associated with a 10 unit increase in each pollutant are reported in table 5. The numbers of patients studied are too small for these estimates to be used for clinical prediction outside of the current study design but are reported here to indicate the general size of the relationships identified. As a marker for the maximum pollutant effect on BHR, $24 \mathrm{~h}$ mean $\mathrm{NO}_{2}$ was used to estimate an approximate increase in within-subject BHR (95\% confidence interval) of $0.54(0.14-0.94)$ doubling doses of methacholine for a $45 \mu \mathrm{g} \cdot \mathrm{m}^{-3}$ increase in $\mathrm{NO}_{2}$ (i.e. in moving from $25-70 \mu \mathrm{g} \cdot \mathrm{m}^{-3}$ ), as of all the pollutants studied, it tended to explain more of the variation in withinsubject BHR.

A similar change in $24 \mathrm{~h}$ lag $\mathrm{NO}_{2}$ was associated with a very modest fall in within-subject FVC of $20 \mathrm{~mL}(0.6 \%)$ from $3,650 \mathrm{~mL}$ to $3,630 \mathrm{~mL}(95 \%$ confidence interval $0-41 \mathrm{~mL})$. For a change in temperature of $3^{\circ} \mathrm{C}\left(13-16^{\circ} \mathrm{C}\right)$, within-subject FEV1 increased from 2,590 to 2,629 mL, representing a $39 \mathrm{~mL}(1.5 \%)$ change $(95 \%$ confidence interval 7-92 $\mathrm{mL}$ ).

\section{Heterogeneity of response}

On reviewing the individual raw data, 24 subjects were identified as responders and 14 as nonresponders. The same 24 individuals responded to each of the three pollutants, demonstrating significant associations, but no responders to ozone were detected. Individual plots of BHR against $24 \mathrm{~h}$ mean $\mathrm{NO}_{2}$ concentration are given in figures 3 and 4 for responders with mild and moderate/ severe BHR, respectively.

Responders tended to be younger than nonresponders (38 vs 44 yrs, respectively) but the difference did not reach statistical significance. Females were equally distributed between the two groups (67 vs 64\%). Mean distance from OPSIS $®(2.4$ vs $2.2 \mathrm{~km})$ and geometric mean PD20FEV1 (1.87 vs $1.54 \mu \mathrm{mol}$, respectively) were also similar in the two groups.

Atopy to any of the four allergens tended to be more common in the responders $(92 \%)$ than nonresponders

Table 5. - Percentage change in BHR for each $10 \mu \mathrm{g} \cdot \mathrm{m}^{-3}$ increase in pollution for each exposure variable

\begin{tabular}{|c|c|c|c|c|}
\hline & $\mathrm{O}_{3}$ & $\mathrm{SO}_{2}$ & $\mathrm{NO}_{2}$ & Smoke \\
\hline $24 \mathrm{~h}$ mean & $\begin{array}{c}0.28 \\
(-16.6 \text { to } 20.6)\end{array}$ & $\begin{array}{c}-6.3^{*} \\
(-13.6 \text { to } 0.6)\end{array}$ & $\begin{array}{c}-6.1^{* *} \\
(-10.9 \text { to }-1.1)\end{array}$ & $\begin{array}{c}-4.3^{*} \\
(-8.0 \text { to }-1.1)\end{array}$ \\
\hline $48 \mathrm{~h}$ mean & $(-20.4$ to 28.6$)$ & $\begin{array}{l}-2.9 \\
(-12.8 \text { to } 8.2)\end{array}$ & $\begin{array}{c}-9.2 * * \\
(-15.7 \text { to }-2.3)\end{array}$ & $\begin{array}{c}-5.2 * \\
(-9.2 \text { to }-1.9)\end{array}$ \\
\hline $24 \mathrm{~h} \mathrm{lag}$ & $\begin{array}{c}2.6 \\
(-22.1 \text { to } 34.9)\end{array}$ & $\begin{array}{c}7.4 \\
(-4.5 \text { to } 20.8)\end{array}$ & $\begin{array}{c}-13.2 * * \\
(-23.2 \text { to }-1.8)\end{array}$ & $\begin{array}{c}-7.1 \\
(-15.9 \text { to } 1.7)\end{array}$ \\
\hline
\end{tabular}

The $95 \%$ confidence intervals are presented in parentheses. Test of significance: *: $\mathrm{p}<0.05 ; * *: \mathrm{p}<0.01$. 


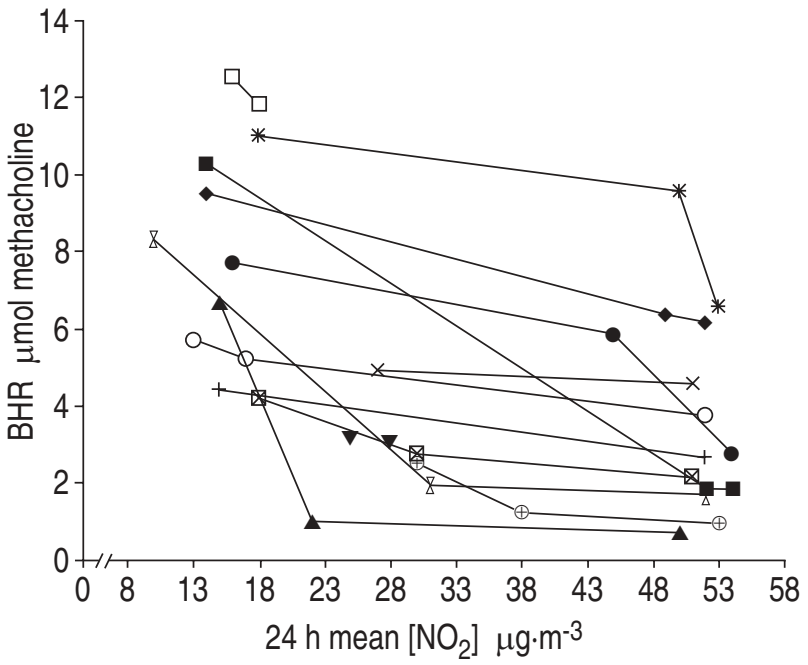

Fig. 3. - Individual plots of bronchial hyperresponsiveness (BHR) against $24 \mathrm{~h}$ mean nitrogen dioxide concentration $\left[\mathrm{NO}_{2}\right]$ in 13 responders with mild BHR (at baseline of 2.5-12.5 $\mu$ mol methacholine).

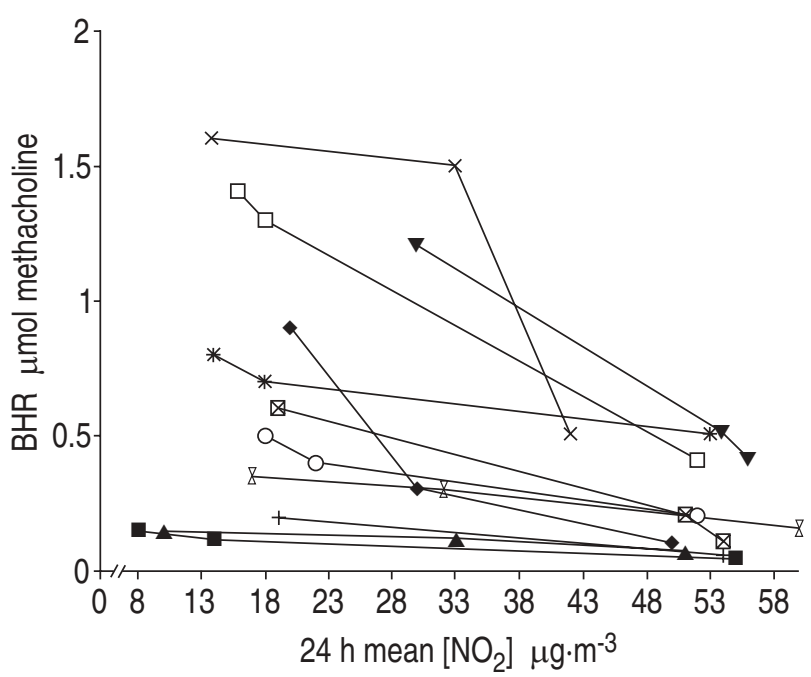

Fig. 4. - Individual plots of bronchial hyperresponsiveness (BHR) against $24 \mathrm{~h}$ mean nitrogen dioxide concentration $\left[\mathrm{NO}_{2}\right]$ in 11 responders with moderate/severe BHR (BHR at baseline of $<2.0 \mu$ mol methacholine). Note the difference in BHR scale compared to fig. 3, mild BHR.

(71\%) but the difference did not reach significance (Chisquared test). Similarly, no significant difference was detected in the proportion of grass pollen atopics occupying the responder compared with the nonresponder group (16 out of 24 or $67 \%$ vs 8 out of 14 or $57 \%$, respectively) although twice as many grass pollen atopics were found to be responders compared to nonresponders (16 out of 24 or $67 \%$ vs 8 out of 24 or $33 \%$, respectively). The proportion of individuals in the responder group on inhaled steroids (17 out of 24 or $71 \%$ ) was also similar to that in the nonresponder group ( 9 out of 14 or $64 \%)$.

\section{Discussion}

This study has shown that asthmatic methacholine BHR varies significantly with background ambient concentrations of summertime $\mathrm{NO}_{2}, \mathrm{SO}_{2}$ and smoke air pollution. The association is, however, only modest when levels of pollution are low, accounting for approximately $10 \%$ of the variation between visits of within-subject BHR. Other factors are, therefore, more important determinants of response, although attempts were made to minimize these where possible.

The study was of a double-blind design in order to minimize selection and testing biases, although the principal investigator was aware of the likely levels of pollution on the days that testing was performed but played no part in the testing of subjects. All subjects were assigned to the same challenge test operator, who used the same equipment on each visit, and were tested at the same time and same place each day to minimize effects due to differences in operator technique and diurnal variation in disease. Efforts were also made to vary the order in which an individual's BHR was tested with respect to the level of pollution, in order to minimize any learning effects through repeated measures. Those subjects experiencing infective exacerbations of their asthma were excluded from analysis, as viruses in particular can potentiate the response to nonspecific bronchoconstrictors [18]. Finally, the study was limited to either life-long nonsmokers or to those who had not smoked for at least $1 \mathrm{yr}$ to avoid any confounding by cigarette smoke [19], and was designed to coincide with the end of the grass pollen season.

The study ran for a total of 68 days and, although BHR measurements were spread over 18 of these, two days in particular (31st July and 18th August) contributed to almost $50 \%$ of the total data collected. How these two days may have influenced the results is difficult to predict as other unmeasured confounding variables may have been in operation. This does, however, seem unlikely, as one would have to assume that the same factors had no influence on each of the remaining 16 days. It is more probable that the fortuitous similarity in temperature and pollen counts on these days allowed the effects of a modest change in pollution to be more easily identified.

For the duration of the study, grass pollen levels were generally very low but were shown to vary significantly with BHR, although the direction of change was towards an improvement in BHR with increasing grass pollen concentrations. This is contrary to the expected potentiation of BHR known to occur during the pollen season [20], and most likely resulted from confounding by other factors. This would appear to be the case, as grass pollen levels were significantly and negatively correlated with $\mathrm{NO}_{2}$ pollution. Daily mean temperatures were also generally low for the duration of the study, reflecting the ordinariness of the summer. Consequently, effects tended to be minimal though not necessarily causally related, as confounding by pollution, pollen or other meteorological variables may have been in operation. Ozone levels were also lower than in previous years and presumably below the threshold required for effects to occur.

Unfortunately, it was not possible to collect information on fungal spores, which are known to provoke asthma and other allergic diseases in sensitive subjects [21, 22]. However, the prevalence of atopy to fungal spores in asthmatics is low, accounting for $13 \%$ of subjects in one study [23]. This suggests that only a minority of individuals in our study group may have been at risk from fungal spore effects but whether the numbers involved 
would have been sufficient to achieve statistical significance remains open to question.

The lack of a general pollution effect on spirometry contrasts with the findings of an earlier study [3], although differences in study design may have been important, particularly as the levels of pollution were similar in the two studies. In the study by HigGins et al. [3], subjects were allowed to make peak expiratory flow rate measurements in a variety of indoor and outdoor environments, whereas participants in the present study were required to rest indoors for a short period of time prior to testing. We believe that this may have provided the correct conditions for a degree of reflex bronchodilatation to occur, resulting in the loss of any transient pollution effects. However, a single association was detected for FVC and $24 \mathrm{~h}$ lag $\mathrm{NO}_{2}$ but was only small, amounting to a $0.6 \%$ fall in FVC for each $45 \mu \mathrm{g} \cdot \mathrm{m}^{-3}$ increase in pollution. This finding is in broad agreement with a similar study in children where pulmonary function was measured on repeated occasions before and after moderate episodes [24]. Concentrations of $\mathrm{NO}_{2}$ were not measured but associations were detected for $\mathrm{SO}_{2}$ and TSP pollution with which it is likely to have correlated.

The lack of an association between BHR and spirometry values suggests not only that BHR can change independently of airway calibre but also that the observed changes in BHR are probably not all that important clinically. Formal assessment of respiratory symptoms prior to each bronchial challenge was not, however, performed because of the possible problem of recall bias. We elected, therefore, to use objective measures of respiratory health which are known to correlate well with the clinical severity of disease [25]. The results suggest that greater changes in pollution, such as those occurring at the start of a pollution episode, are required to worsen pulmonary function to the extent that symptoms develop. Had effects both on BHR and pulmonary function been detected, then adjustment of BHR values would have been necessary as the response to bronchoconstrictors is known to correlate with prechallenge spirometry [26].

In this study, measurement of background ambient concentrations of pollution were used to estimate personal exposure, although it is recognized that there are limitations to this approach, particularly as the majority of people spend over $95 \%$ of their day indoors [27], where the concentrations of outdoor pollutants are generally lower but may rise to significant levels under exceptional conditions [28]. Our results from this and a previous study suggest that measurement of background concentrations of pollution offer a practical alternative to personal sampling methods, which currently provide information on a limited number of pollutants and are subject to varying degrees of inaccuracy.

In common with most epidemiological studies on air pollution, we have observed a high degree of intercorrelation between the different explanatory variables and have not, therefore, attempted to apportion blame to a specific pollutant. The evidence from environmental chamber studies linking $\mathrm{NO}_{2}$ exposure to the potentiation of asthmatic BHR is inconsistent [29-32], whereas the effects of smoke and $\mathrm{SO}_{2}$ on BHR are yet to be studied. Furthermore, measurements of other pollutants, such as acid aerosols and particulate matter with an aerodynamic diameter $\leq 10 \mu \mathrm{m}$ (PM10) were not performed in this study. Such pollutants are likely to have correlated with the measured levels of $\mathrm{NO}_{2}, \mathrm{SO}_{2}$ and smoke, although concentrations of acid aerosol and PM10 would have been most closely related to $\mathrm{O}_{3}$ and smoke, respectively. For the duration of the study, however, disappointingly low levels of $\mathrm{O}_{3}$ were encountered, making it increasingly unlikely that significant acid aerosol production took place.

Whether the results of this study are representative of all nonsmoking asthmatics remains open to question, particularly in view of the low response rate (which is most likely to be related to the requirement for study subjects to undergo repeated tests of bronchial reactivity) and the presence of a distinct heterogeneity in the response of participating subjects. This heterogeneity of response appears to be unrelated to basic demographic details but may reflect variation in individual sensitivity to pollution, as in the laboratory exposures of asthmatic subjects to $\mathrm{O}_{3}$ or $\mathrm{SO}_{2}$ are known to produce a spectrum of physiological effects $[33,34]$.

The results of this study suggest that at levels below current WHO Guidelines for Health, changes (rather than the crossing of absolute thresholds) in the concentrations of certain traffic-related air pollutants are capable of potentiating airway inflammation in nonsmoking asthmatic subjects, and that these effects can be detected by repeated measurement of methacholine bronchial hyperresponsiveness. Potentiation of asthmatic bronchial hyperresponsiveness may, therefore, underlie the increase in respiratory morbidity known to accompany pollution episodes [35].

Acknowledgements: The authors gratefully acknowledge the support of the two GP surgeries involved and express their sincere thanks to all participating subjects.

\section{References}

1. Koenig JQ, Covert DS, Hanley QS, Van Belle G, Pierson WE. Prior exposure to ozone potentiates subsequent response to sulfur dioxide in adolescent asthmatic subjects. Am Rev Respir Dis 1990; 141: 377-380.

2. Hazucha MJ, Folinsbee LJ, Seal E, Bromberg PA. Lung function response of healthy women after sequential exposure to $\mathrm{NO}_{2}$ and $\mathrm{O}_{3}$. Am J Respir Crit Care Med 1994; 150: 642-647.

3. Higgins BG, Francis HC, Yates CJ, et al. Effects of air pollution on symptoms and peak expiratory flow measurements in subjects with chronic obstruction airways disease. Thorax 1995; 50: 149-155.

4. Linn WS, Avol EL, Shamoo DA, et al. Effect of metaproterenol sulfate on mild asthmatics' response to sulfur dioxide exposure and exercise. Arch Environ Health 1988; 43: 399-406.

5. Seltzer J, Bigby BG, Stulbarg M, et al. $\mathrm{O}_{3}$-induced change in bronchial reactivity to methacholine and airway inflammation in humans. J Appl Physiol 1986; 60(4): 1321-1326.

6. Hazucha MJ, Bates DV, Bromberg PA. Mechanism of action of ozone on the human lung. J Appl Physiol 1989; 67(4): 1535-1541.

7. Molfino NA, Wright SC, Katz I, et al. Effect of low 
concentrations of ozone on inhaled allergen responses in asthmatic subjects. Lancet 1991; 338: 199-203.

8. Tunnicliffe WS, Burge PS, Ayres JG. Effect of domestic concentrations of nitrogen dioxide on airway responses to inhaled allergen in asthmatic subjects. Lancet 1994; 344: 1733-1736.

9. Peat JK, Van den Berg RH, Green WF, Mellis CM, Leeder SR. Changing prevalence of asthma in Australian children. BMJ 1994; 308: 1591-1596.

10. Department of the Environment: Digest of environmental protection and water statistics. No. 14 1991, HMSO, London, 1992.

11. Bradley BL, Azzawi M, Jacobson M, et al. Eosinophils, T-lymphocytes, mast cells, neutrophils, and macrophages in bronchial biopsy specimens from atopic subjects with asthma: comparison with biopsy specimens from atopic subjects without asthma and normal control subjects and relationship to bronchial hyperresponsiveness. J Allergy Clin Immunol 1991; 88: 661-674.

12. Wardlaw AJ, Durmette S, Gleich GJ, Collins JV, Kay $\mathrm{AB}$. Eosinophils and mast cells in bronchoalveolar lavage in subjects with rnild asthma: relationship to bronchial hyperreactivity. Am Rev Respir Dis 1988; 137: 62-69.

13. Yan K, Salome C, Woolcock AJ. Rapid method for measurement of bronchial responsiveness. Thorax 1983; 38: 760-765.

14. INERIS. Institut National de l'Environment Industriel et des Risques. AIR-JPo-No.3421/93. Study 484504.

15. Harrison RM. Important air pollutants and their chemical analysis. In: Harrison RM, ed. Pollution: Causes, Effects and Control. Cambridge, Royal Society of Chemistry, 1990; pp. 127-155.

16. Davies OL (Ed.). Statistical methods in research and production (with special reference to the chemical industry). London, Oliver \& Boyd, 1967.

17. World Health Organization. Air Quality Guidelines for Europe. WHO Regional Publications. European Series No. 23, Copenhagen, 1987.

18. Sterk PJ. Virus-induced airway hyperresponsiveness in man. Eur Respir J 1993; 6: 894-902.

19. Gerrard JW, Cockcroft DW, Mink JT, Cotton DJ, Poonawala $\mathrm{R}$, Dosman JA. Increased nonspecific bronchial reactivity in cigarette smokers with normal lung function. Am Rev Respir Dis 1980; 122: 577-581.

20. Boulet L-P, Cartier A, Thomson NC, Roberts RS, Dolovich $\mathrm{J}$, Hargreave FE. Asthma and increases in nonallergic bronchial responsiveness from seasonal pollen exposure. J Allergy Clin Immunol 1983; 71: 399-406.
21. Hyde HA. Atmospheric pollen and spores in relation to allergy: I. Clin Allergy 1972; 2: 153-179.

22. Gravesen S. Fungi as a cause of allergic disease. Allergy 1979; 34: 135.

23. Burr ML, Mullins J, Merrett TG, Stott NCH. Indoor moulds and asthma. J R Soc Health 1988; 3: 99-101.

24. Dockery DW, Ware JH, Ferris BG, Speizer FE, Cook NR, Herman SM. Change in pulmonary function in children associated with air pollution episodes. JAPCA 1982; 32: 937-942.

25. Cockcroft DW, Killian DN, Mellon JJA, Hargreave FE. Bronchial reactivity to inhaled histamine: a method and clinical survey. Clin Allergy 1977; 7: 235-243.

26. Tattersfield AE. Relationship of resting airway caliber to measurements of airway responsiveness in man: airway responsiveness; measurement + interpretation. Hargreaves and Woolcock, 1985.

27. Spengler JD. Indoor air pollution. N Engl Reg Allergy Proc 1986; 6: 126-134

28. Hoek G, Brunekreef B, Hofschreuder P. Indoor exposure to airborne particles and nitrogen dioxide during an air pollution episode. J Air Pollut Control Assoc 1989; 39: $1348-1349$.

29. Orehek J, Massari JP, Gayrard P, Grimaud C, Charpin J. Effect of short-term, low-level nitrogen dioxide exposure on bronchial sensitivity of asthmatic patients. J Clin Invest 1976; 57: 301-307.

30. Mohsenin V. Airway responses to nitrogen dioxide in asthmatic subjects. J Toxicol Environ Health 1987; 22: 371-380.

31. Jorres R, Magnussen H. Effect of $0.25 \mathrm{ppm}$ nitrogen dioxide on the airway response to methacholine in asymptomatic asthmatic patients. Lung 1991; 169: 77-85.

32. Kleinman MT, Bailey RM, Linn WS, et al. Effects of $0.2 \mathrm{ppm}$ nitrogen dioxide on pulmonary function and response to bronchoprovocation in asthmatics. J Toxicol Environ Health 1983; 12: 815-826.

33. Horstman D, Roger LJ, Kehrl H, Hazucha M. Airway sensitivity of asthmatics to sulfur dioxide. Toxicol Ind Health 1986; 2: 289-298.

34. Folinsbee LJ, McDonnell WF, Horstman DH. Pulmonary function and symptom responses after 6.6 hour exposure to $0.12 \mathrm{ppm}$ ozone with moderate exercise. J Air Pollut Control Assoc 1988; 38: 28-35.

35. Walters S, Griffiths RK, Ayres JG. Temporal association between hospital admissions for asthma in Birmingham and ambient levels of sulphur dioxide and smoke. Thorax 1994; 49: 133-140. 